\title{
Sizing and Simulation of Powertrain of Three-Wheeler Electric Vehicle
}

Omkar Tade* and Jyoti Kale ${ }^{\#}$

*Student, Department of Mechanical Engineering, College of Engineering, Pune, India

${ }^{\#}$ Manager, Technology Group, Automotive Research Association of India, Pune, India

(Received 15 July 2021; Accepted 25 September 2021)

DOI: https://doi.org/10.36224/ijes.140304

\begin{abstract}
This research paper presents the study of designing, modelling and validating the results of simulation of powertrain of 3wheeler electric vehicle with literature results. According to force and torque requirement at wheels, required power rating of motor is calculated. Indian driving cycle is used to calculate energy consumption by vehicle. Battery chemistry and sizing is selected according to energy requirement. According to requirement of power and constraints, type of motor is selected along with gear reduction calculation to achieve required torque and acceleration. For precise control of motor speed because of road profiles and traffic conditions control strategy is designed. All these subsystems are modelled on simulation platform and comparison with theoretical calculations will be carried out. The objective of this paper is to design, model and optimize the performance of electric vehicle in terms of powertrain and try to match the performance parameters with conventional IC-engine vehicle. This paper comprises of design in gelectric subsystems, creating control strategies for better performance and model-based simulation to check the performance
\end{abstract}

Keywords: Electric Vehicle, Motor Selection, Powertrain, Retrofitment, Simulation

\section{Introduction}

3-Wheeler is an important means of transportation which contribute to the huge percentage in public and goods transport. With a need for motorized system of transportation the rickshaw has evolved over the years. In this era where petroleum is facing a decline courtesy of non- renewable in nature, electric vehicles will be expected to carry the future mobility. Adding to recent strict emission norms implemented across the world, it is a huge challenge to the automotive manufacturers in reducing the complexity of after treatment devices despite its promising nature to counter emission norms. As compared to conventional ICEthree-wheeler, EV's performance lacks in range, max speed, gradeability etc. Extra weight EV components mainly Battery affects the performance of EV [2]. So, we need to use different strategies in powertrain fore .g., Modification of gear reductions, driveline components controller strategies etc. to enhance performance of electric vehicle to match up with conventional ICE vehicle.

\section{Retrofitment}

It is process of process of converting a combustion engine vehicle into an electric vehicle. It includes replacing conventional powertrain with electric powertrain components [3], [4]. Although designing a retro-fitment kit involves numerous technical and mechanical constraints, it is cheaper than designing a new electric vehicle right from scratch. It also reduces the effective maintenance cost of vehicle. The installation of a retro-fitment kit can alter the designed vehicle dynamics of the vehicle. Also, not all components which are required for retro-fitment kit is indigenously available. Theretro-fitment 
kit/Electric Propulsion Kit as well as retrofitted vehicle must conform to the standards and tests mentioned in AIS-123(Part- 3) [5].

\section{Benchmarking vehicle data}

Benchmarking involves a structured comparison between similar products, services or processes on some dimensions of performance. It can be used to compare the availability and delivery of features in a product. It offers comparison of the performance of vehicle, identification of areas of improvement, setting performance expectations etc.

Table 1: Selected Vehicle Data
\begin{tabular}{|c|l|c|}
\hline Type & Diesel & \\
\hline Engine & 470.5 & $\mathrm{cc}$ \\
\hline Max Power & 6.74 & $\mathrm{~kW}$ \\
\hline & 3400 & $@, \mathrm{rpm}$ \\
\hline Max Torque & 23.18 & $\mathrm{Nm}$ \\
\hline & 2000 & $@, \mathrm{rpm}$ \\
\hline Gradeability & 18 & $\%$ \\
\hline & 10.2 & $\mathrm{deg}$ \\
\hline GVW & 965 & $\mathrm{~kg}$ \\
\hline
\end{tabular}

\section{Motor sizing and selection}

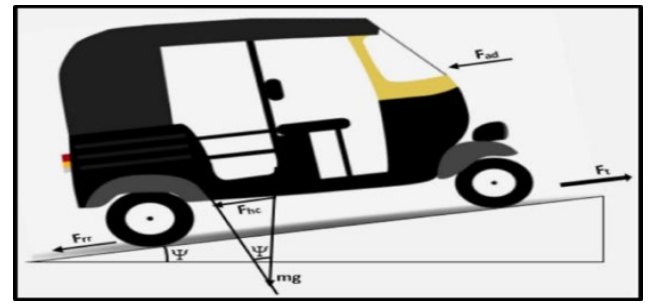

Figure 1: Resistance on Vehicle

The different resistance acting on vehicle are [6]:

1) Rolling Resistance: Rolling Resistance is the opposing force that the vehicle has to overcome due to the rolling motion between the wheels and the surface of motion of the vehicle. It is given by,

$$
\mathrm{F}_{\mathrm{r}}=\mathrm{f}_{\mathrm{r}} \mathrm{mg} \cos \alpha
$$

Where, $f_{r}=$ rolling resistance coefficient of tire, $\alpha=$ road slope angle.

2) Grade Resistance:Grade resistance is the form of gravitational force. It is the force that tends to pull the vehicle back when it is climbing an inclined surface. It is givenby,

$$
\mathrm{F}_{\mathrm{g}}=\operatorname{mgsin} \alpha
$$

3) Aerodynamic Resistance:The resistance offered by air in the atmosphere while vehicle travelling through it is known as aerodynamic drag resistance. It is givenby,

$$
\mathrm{F}_{\mathrm{d}}={ }^{1} \rho \mathrm{C}_{\mathrm{d}} \mathrm{A}_{\mathrm{f}} \mathrm{v}^{2}
$$

Where, $\rho=$ density of air $\left(\mathrm{kg} / \mathrm{m}^{3}\right), \mathrm{C}_{\mathrm{d}}=$ Aerodynamic drag coefficient, $\mathrm{A}_{\mathrm{f}}=$ Frontal area $\left(\mathrm{m}^{2}\right), \mathrm{v}=$ vehicle speed $(\mathrm{m} / \mathrm{s})$.

4) Inertia Resistance: Inertia force is the force that helps the vehicle to reach a predefined speed form 
rest in a specified period of time. The motor torque bears a direct relationship with the acceleration force. It is given by,

$$
F_{i}=m a
$$

Total resistance acting on vehicle is given by,

$$
\mathrm{F}_{\text {total }}=\mathrm{F}_{\mathrm{r}}+\mathrm{F}_{\mathrm{g}}+\mathrm{F}_{\mathrm{d}}+\mathrm{F}_{\mathrm{i}}
$$

The power required for motor can be calculated by following formula,

$$
\mathrm{P}_{\mathrm{ext}}=\text { Motor Power }(\mathrm{W}) * \eta_{\mathrm{d}}=\mathrm{F}_{\text {total }} * \mathrm{v}(\mathrm{m} / \mathrm{s})
$$

Table 2:CalculationParameters

\begin{tabular}{|c|c|c|}
\hline $\mathrm{C}_{\mathrm{d}}$ & 0.44 & \\
\hline$\eta_{\mathrm{d}}$ & 0.8 & \\
\hline$\rho$ & 1.12 & $\mathrm{~kg} / \mathrm{m} 3$ \\
\hline $\mathrm{f}_{\mathrm{I}}$ & 0.015 & \\
\hline $\mathrm{A}_{\mathrm{f}}$ & 2 & $\mathrm{~m} 2$ \\
\hline $\mathrm{v}_{\max }$ & 55 & $\mathrm{kmph}$ \\
\hline & 15.27778 & $\mathrm{~m} / \mathrm{s}$ \\
\hline $\mathrm{v}_{\text {grad }}$ & 5 & $\mathrm{kmph}$ \\
\hline & 1.388889 & $\mathrm{~m} / \mathrm{s}$ \\
\hline $\mathrm{R}_{\mathrm{w}}$ & 0.24 & $\mathrm{~m}$ \\
\hline
\end{tabular}

Table 3: Power Calculation

\begin{tabular}{|c|c|c|}
\hline Aerodynamic Resistance & 0.95 & $\mathrm{~N}$ \\
\hline Rolling Resistance & 138.89 & $\mathrm{~N}$ \\
\hline Grade Resistance & 1967.24 & $\mathrm{~N}$ \\
\hline Inertia Resistance & 1228.58 & $\mathrm{~N}$ \\
\hline Total Resistance & 3335.68 & $\mathrm{~N}$ \\
\hline P $_{\text {motor }}$ & $\mathbf{5 . 7 9}$ & $\mathbf{k W}$ \\
\hline
\end{tabular}

\subsection{Power Calculation}

Calculations are carried out for different conditions like maximum speed, maximum gradeability and Indian Drive Cycle (IDC). Amongst them, maximum power required for maximum gradeability condition. Power calculation is carried out for maximum gradeability of $10.2^{\circ}$ slope at speed of $5 \mathrm{~km} / \mathrm{hr}$. Average acceleration is taken as $1.27 \mathrm{~m} / \mathrm{s}^{2}$.

\subsection{Motor Selection}

Motor is selected by comparing parameters of different types of EV motors. The motors which are widely used are Permanent Magnet Synchronous Motor (PMSM),Switched Reluctance Motor(SRM), Brushless DCMotor(BLDC) and Induction Motor [7]. The motors are compared on basis of different parameters like efficiency, cost, ease of control, starting Torque, power output, life, maintenance, noise and size [8]. After comparison the specification of selected motor are:

Table IV. Selected Motor Specification

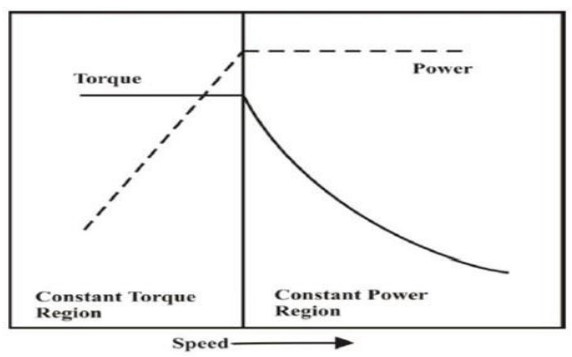

\begin{tabular}{|c|c|}
\hline Motor type & PMSM \\
\hline Voltage Level & $48 \mathrm{~V}$ \\
\hline Max Torque & $42 \mathrm{Nm}$ \\
\hline Peak Power & $7 \mathrm{~kW}$ \\
\hline Max Speed & $9000 \mathrm{rpm}$ \\
\hline
\end{tabular}

Figure 2: Ideal Torque-Power Curve for EV

\section{Battery sizing and selection}

\subsection{Energy Consumption [5]}


a. Considering vehicle running for IDC cycle, the total resistance force on vehicle $F_{\text {total }}$ is $210 \mathrm{~N}$.

b. IDC cycle runs for $3.948 \mathrm{~km}$ and 648 seconds. The average power consumed by vehicle is given by, $\mathrm{P}_{\mathrm{avg}}=F_{\text {total }} * \mathrm{~V}_{\mathrm{avg}}$.

c. Total energy required can be calculated by integration power consumed over IDC time cycle, $\mathrm{E}_{\text {total }}=$ $P_{\text {avg }} *\left(t_{\text {cycle }} / 3600\right)$.

d. Average energy required per $\mathrm{km}$ (IDC) is given by, $E_{\mathrm{avg}}=\mathrm{E}_{\text {total }}\left(2-\eta_{\mathrm{d}}\right)$.

e. For designing vehicle for $105 \mathrm{~km}$ range, battery capacity of $7.257 \mathrm{kWhr}(144 \mathrm{Ah})$ is required.

\subsection{Battery Chemistry}

Currently NiMH and Li-ion batteries are used in electric vehicles worldwide. NiMH is an old and mature technology[9]. But, due to ability of higher specific energy and specific power, li- ion batteries demand is increasing rapidly. Li-ion batteries provide advantages like low self- discharge rate, smaller in size, faster charging and higher energy density. In 3-W application, due to lack of available space and weight constraints Li-ion batteries are preferred overNiMH batteries.

Table 5: Selected Battery Specifications

\begin{tabular}{|c|l|}
\hline Item & Specification \\
\hline Nominal Energy & $3.5 \mathrm{Ah}$ \\
\hline Pack Voltage & $50.8 \mathrm{~V}$ \\
\hline Pack Capacity & $144 \mathrm{Ah}$ \\
\hline Cell Nominal Voltage & $3.63 \mathrm{~V}$ \\
\hline Cell Constant Voltage & $4.2 \mathrm{~V}$ \\
\hline Cell Cutoff Voltage & $2.5 \mathrm{~V}$ \\
\hline Constant Current & $1 \mathrm{C}$ \\
\hline Operating Temperature & -20 to $45^{\circ} \mathrm{C}$ \\
\hline
\end{tabular}

\section{Simulation model}

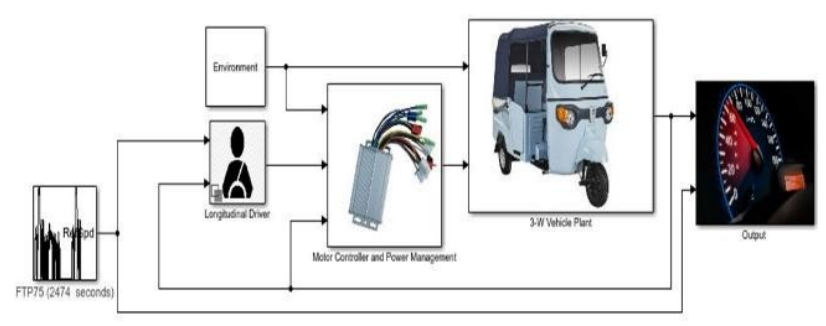

Figure 3: Simulation Model

\section{Results}

1. Velocity Profile: FTP-75 profile is fed asinput

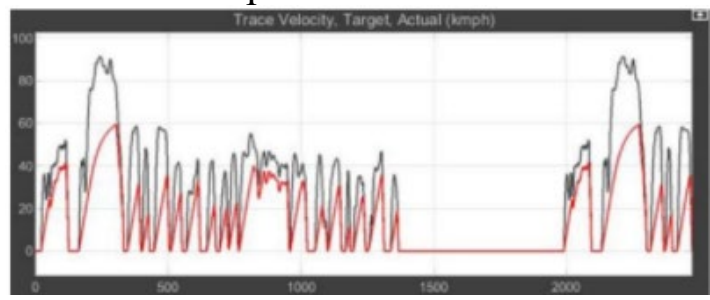

Figure 4: Velocity Profile 
2. Motor torque:

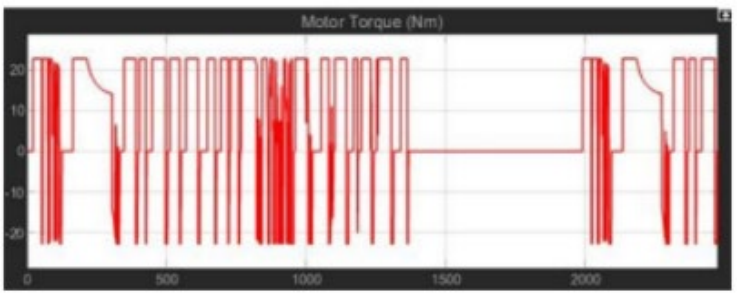

Figure 5: Motor torque profile

3. Motor RPM

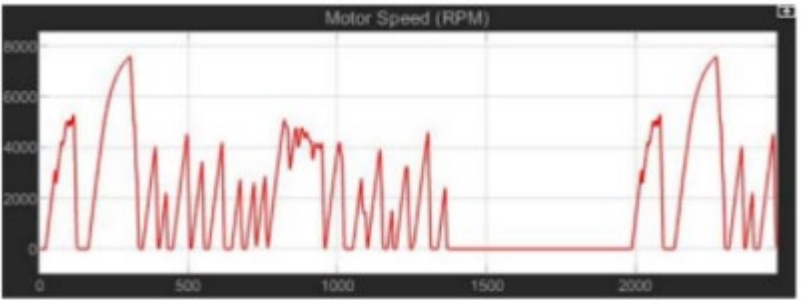

Figure 6: Motor RPM

4. Range Comparison: Vehicle is simulated with regeneration and without regeneration mode. Range outputs given by model are compared.

Table 4: Range Comparison

\begin{tabular}{|c|c|c|c|c|}
\hline \multirow[b]{2}{*}{ Comparison } & \multicolumn{2}{|c|}{ Without Regeneration } & \multicolumn{2}{|c|}{ With Regeneration } \\
\hline & Theoretical & Practical & Theoretical & Practical \\
\hline Initial Capacity (Ah) & 144 & 136 & 144 & 136 \\
\hline Final Capacity (Ah) & 3 & 10 & 3 & 10 \\
\hline Initial SOC\% & 100 & 95 & 100 & 95 \\
\hline Final SOC\% & 0 & 10 & 0 & 10 \\
\hline Range (km) & 90 & 77.47 & 102 & 89.938 \\
\hline
\end{tabular}

\section{Validation}

For validation of simulation model, reference paper is used and results are compared with reference results to check the accuracy of the model [1]. This paper presents the low-cost EV platform intended to provide a modular and scalable platform for 2 and 3 wheelers that is robust and meets the desired performance characteristics. The paper discusses the integration effort involved and provide a costing perspective for all the components for the electrified drivetrain. The system design, component sizing, simulation activities are explained. The specifications and parameters of vehicle from reference paper are fed to simulation model and their results are compared.

Table 6: Validation Results

\begin{tabular}{|c|c|}
\hline Drive Cycle & Range \\
\hline FTP 75 & 89.87 \\
\hline NEDC & 85.47 \\
\hline WLTP Class 3 & 87.85 \\
\hline Average Range & 87.73 \\
\hline Research Paper Range & 100 \\
\hline \% Error & $\mathbf{1 2 . 2 7} \%$ \\
\hline
\end{tabular}




\section{Conclusion}

In this work, the literature review on $3-\mathrm{W}$ electric vehicles has been done to study about the modelling methodologies, sizing the components required for vehicle and performance. Initially, a survey is done to study market of Retrofitment technology, available 3-W ICE and electric vehicles. After doing market study, benchmarked vehicle is finalized and target performance parameters are finalized. Motor and battery sizing is done using target parameters, FAME-II standards and analytical calculations. After comparing Permanent Magnet Synchronous Motor (PMSM) and Li-ion battery is shortlisted. Modelling and simulation of vehicle is done and results are compared with calculations. To check whether model works perfectly, results of simulation are compared with research paper results. PMSMof $7 \mathrm{kWpeak}$ powerand144AhLi-ionbatterypackisselected.Outputsofmodelareasfollows: TopSpeed: 10\% increase in top speed of retrofitted vehicle as compared to benchmarked ICE vehicle. Range: $20 \%$ increase in range of retrofitted vehicle as compared to average range of available $3-\mathrm{W}$ electricvehicles.35\% increase in mileage per fuel recharge as compared to benchmarked ICE vehicle. Gradeability: Gradeability of $18 \%$ was considered while sizing of powertrain components which is almost equal to performance of benchmarked ICEvehicle.

\section{References}

[1] Ajith Kumaran, Sarah Ahmad, Raviteja Chanumolu, Gaurav Sadekar, Mohan Joshi, and Vijay Sharma, "Low Cost EV Platform for Three Wheeler Electrification Development", SAE International: 2019-26-0120, January2019.

[2] Deepanjan Majumdar and Tushar Jash, "Merits and Challenges of E-Rickshaw as An Alternative formofPublicRoadTransportSystem:ACaseStudyintheStateofWestBengalinIndia”,Energy Procedia: 79 (2015) $307-314$.

[3] Kiran B Pattar, Praveen Kumar R H, Rahul Raj K Jain and Sharanbasappa S Patil, "Methodology for Retrofitting Electric Power Train in Conventional Powertrain-based Three-Wheeler", Journal of Applied Research on Industrial Engineering: Vol. 5, No. 3 (2018) 263-270, Oct2018.

[4] Karthik D M, Arun C Giriyapur, "Retrofitting of an Engine Powered Vehicle into an Electric Vehicle", Second International Conference on Smart Systems and Inventive Technology, ISBN:978-1-7281-21192,2019.

[5] Automotive Research Association of India, "AIS 123 (PART 3): CMVR Type Approval of Electric Propulsion Kit Intended for Conversion of vehicles for Pure Electric Operation",2018.

[6] Sreejith R. and K.R. Rajagopa, "An Insight into Motor and Battery Selections for Three-Wheeler Electric Vehicle", IEEE International Conference on Power Electronics. Intelligent Control and Energy Systems:2016.

[7] Nasser Hashernnia and Behzad Asaei, "Comparative Study of Using Different Electric Motors in theElectricVehicles",2008InternationalConferenceonElectricalMachines:1257,October2008.

[8] Merve YILDIRIM, Mehmet POLAT and Hasan KÜRÜM, "A Survey on Comparison of Electric Motor Types and Drives Used For Electric Vehicles", 16th International Power Electronics and Motion Control Conference and Exposition: EPEPEMC.2014.6980715, Sept2014.

[9] Kwo Young, Caisheng Wang, Le Yi Wang, and Kai Strunz, "Electric Vehicle Battery Technologies", Springer Science 2013:10.1007/978-1-4614-0134-6_2.

[10] Kwo Young, Caisheng Wang, Le Yi Wang, and Kai Strunz, "Electric Vehicle Battery Technologies", Springer Science 2013: 10.1007/978-1-4614-0134-6_2. 